\section{Effectiveness and safety of ruxolitinib for the treatment of refractory systemic idiopathic juvenile arthritis like associated with interstitial lung disease : a case report}

We read with interest the report of a series of 61 patients with systemic juvenile idiopathic arthritis (s-JIA) or s-JIA-like associated with high-fatality lung diseases. ${ }^{1}$ Lung disease was associated with digital clubbing, a high frequency of anaphylactic reactions to tocilizumab, and macrophage activation syndrome (MAS). Because of the low 5 -year survival probability of $42 \%$, there is an urgent need to identify efficient drugs to treat such patients. Herein we report the effectiveness and safety of ruxolitinib in one patient demonstrating clinical and radiological characteristics consistent to those reported by Saper et al

A 2-year-old girl born to non-consanguineous parents presented with s-JIA-like since the age of 12 months, including recurring episodes of unexplained fever, urticaria, arthralgia, poor general health status, leukocytosis and elevated serum C-reactive protein (CRP). The use of corticosteroids resulted in a complete remission but the patient relapsed when prednisone was tapered below $0.5 \mathrm{mg} / \mathrm{kg} / \mathrm{day}$. Owing to this corticosteroid dependence, the patient received several lines of biological agents from the age 15-22 months, none of which was either effective nor tolerated. Anakinra had no benefit on the patient's features, and was replaced by canakinumab-but which resulted in a probable drug reaction with eosinophilia and systemic symptoms and a MAS after the third injection. Finally, a third line with tocilizumab led to severe anaphylactic reactions after the second infusion. At age 34 months, the patient developed acute digital clubbing without any respiratory symptoms. Chest CT scan showed a diffuse interstitial disease with interlobular septal thickenings, bronchovascular bundles thickenings, ground glass opacities with a peripheral and lower lobes predominance, and enlargement of mediastinal lymph nodes (figure 1). Bronchoalveolar lavage (BAL) fluid showed 250000 cells / $\mathrm{mL}$ (macrophages: 66\%, neutrophils: 27\%, lymphocytes: 7\%). Microbiological investigations were all negative. A whole exome sequencing did not identify any causal mutation.

The expression of interferon (IFN)-stimulated genes in the whole blood of the patient was normal on two occasions, and increased once while the patient received anti-interleukin-1 treatment. Immunophenotyping showed normal counts of T cell, B cell and natural killer (NK) lymphocytes. Further study showed that, among memory $\mathrm{CD}^{+}{ }^{+} \mathrm{T}$ cells, the patient had frequencies of Th1 cells well above the control range, and decreased frequencies of Th17 cells (figure 2).

At the age of 4 , the patient was treated with the Janus kinase $1 / 2$ selective inhibitor ruxolitinib $(1 \mathrm{mg} / \mathrm{kg} /$ day $)$ in association with oral prednisone $(0.5 \mathrm{mg} / \mathrm{kg} /$ day $)$ and 3 monthly intravenous infusions

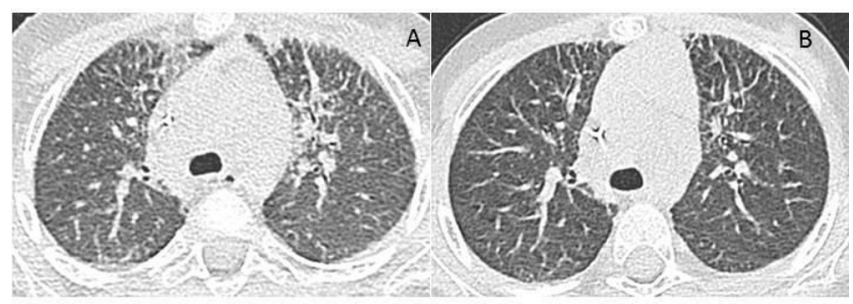

Figure 1 Radiological response to JAK1/JAK2 blockade with ruxolitininb . (A) Chest CT scan before the initiation of ruxolitinib. (B) Chest CT scan 12 months after the initiation of ruxolitinib.

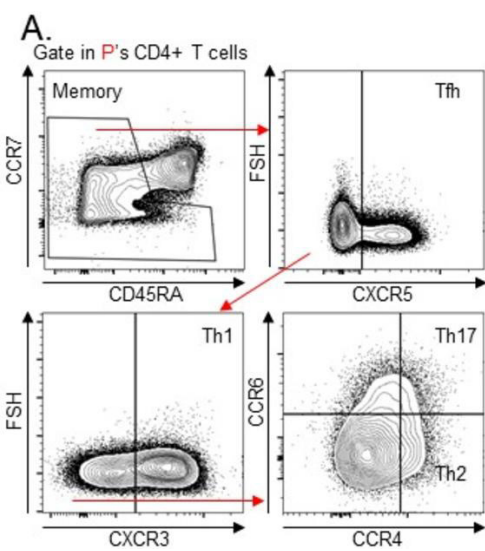

B. ${ }_{\text {requency in memory } \mathrm{CD} 4+\mathrm{T} \text { cells }}$
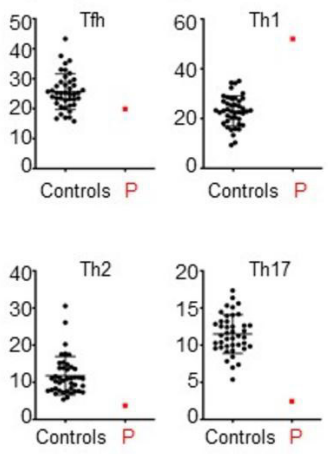

Figure 2 T helper immunophenotyping. (A) Gating strategy in the patient's peripheral blood mononuclear cells (PBMCs) for T helper immunophenotyping. (B) Representative fluorescence activated cell sorting (FACS) plots are presented. The horizontal bars represent the mean+/-SD. Frequencies of T helper subsets within the $\mathrm{CD} 4^{+}$memory compartment in controls and P. Subsets were defined as follows: Th1 (CXCR5 $\left.{ }^{-} \mathrm{CXCR3}^{+} \mathrm{CCR}^{-}{ }^{-} \mathrm{CCR} 6^{-}\right)$, Th2 (CXCR5 $\left.{ }^{-} \mathrm{CXCR3} 3^{-} \mathrm{CCR}^{+} \mathrm{CCR6}^{-}\right)$, Th17 $\left(\mathrm{CXCR}^{-}{ }^{-} \mathrm{CXCR} 3^{-} \mathrm{CCR}^{+} \mathrm{CCR6}^{+}\right)$and Tfh $\left(\mathrm{CXCR} 5^{+}\right)$.

of methylprednisolone $\left(600 \mathrm{mg} / \mathrm{m}^{2}\right)$. At last follow-up, 15 months post initiation of ruxolitinib, febrile attacks remitted, CRP value was normal, prednisone was tapered to $0.1 \mathrm{mg} / \mathrm{kg} / \mathrm{day}$, and methylprednisolone dosage was progressively decreased to one infusion $\left(300 \mathrm{mg} / \mathrm{m}^{2}\right)$ every 6 weeks. Chest CT scan abnormalities decreased (figure 1). Oxygen saturation increased from $92 \%$ to $100 \%$. There was a catch-up growth with an improvement of the height $\mathrm{Z}$-scores from -3 to -2 . Ruxolitinib was well tolerated.

Our patient demonstrates features similar to those reported in the series of Saper et al. An upregulation of genes related to the IFN $\gamma$ reponse both in the (BAL) fluid and lung tissue was demonstrated in some patients from this series. ${ }^{2}$ In line with a putative pathogenic role of IFN $\gamma$ signaling, a high frequency of MAS was reported. The observation in our patient of (1) elevated frequency of Th1 cells, main producers of IFN $\gamma^{3}$, and (2) a clinical response to ruxolitinib, blocking the IFN $\gamma$ signalling, although not selectively, ${ }^{45}$ is consistent with this hypothesis. Although no definite conclusion can be drawn from this single case, our report suggests that ruxolitinib may represent a valid therapeutic option to be tested early in patients with s-AJI associated with severe early-onset lung disease.

Brigitte Bader-Meunier $\odot{ }^{1,2}$ Alice Hadchouel, ${ }^{3}$ Laureline Berteloot, ${ }^{4}$ Laura Polivka, ${ }^{5}$ Vivien Béziat, ${ }^{6,7}$ Jean-Laurent Casanova, ${ }^{1,6,7,8,9}$ Romain Lévy ${ }^{1,6,7}$

${ }^{1}$ Pediatric Hematology-Immunology and Rheumatology Unit, Hôpital Necker-Enfants Malades, AP-HP Centre, Paris, France

${ }^{2}$ INSERM UMR 1163, Laboratory of Immunogenetics of Paediatric Autoimmunity, Institut Imagine, Paris, France

${ }^{3}$ Pediatric Pneumology Unit, Hôpital Necker-Enfants Malades, AP-HP Centre, Paris, France

${ }^{4}$ Pediatric Radiology Unit, Hôpital Necker-Enfants Malades, AP-HP Centre, Paris, France

${ }^{5}$ Dermatology and Pediatric Dermatology Unit, Hôpital Necker-Enfants Malades, AP-HP Centre, Paris, France

${ }^{6}$ Laboratory of Human Genetics of Infectious Diseases, Necker Branch, INSERM UMR 1163 , Paris, France

${ }^{7}$ Paris Descartes University, Imagine Institute, Paris, France

${ }^{8}$ St Giles Laboratory of Human Genetics of Infectious Diseases, Rockefeller Branch, The Rockefeller University, New York, NY, USA

${ }^{9}$ Howard Hughes Medical Institute, New York, NY, USA

Correspondence to Dr Brigitte Bader-Meunier, Service d'ImmunologieHematologie et Rhumatologie Pediatrique, Hopital universitaire Necker-Enfants malades, Paris 75015, France; brigitte.bader-meunier@aphp.fr 
Contributors LP and BB-M collected clinical data. VB, J-LC and RL performed the immunological experiments and analysed data. BB-M, LP, AH and LB wrote the paper. $A H$ and $L B$ analysed the pulmonary clinical and radiological data. RL and BB-M supervised the study. All authors have read final approval of the version published.

Funding The authors have not declared a specific grant for this research from any funding agency in the public, commercial or not-for-profit sectors.

Competing interests None declared.

Patient consent for publication Parental/guardian consent obtained.

Provenance and peer review Not commissioned; internally peer reviewed.

(c) Author(s) (or their employer(s)) 2020. No commercial re-use. See rights and permissions. Published by BMJ.

\section{(A) Check for updates}

To cite Bader-Meunier B, Hadchouel A, Berteloot L, et al.

Ann Rheum Dis Epub ahead of print: [please include Day Month Year]. doi:10.1136/ annrheumdis-2020-216983

Received 12 January 2020
Accepted 15 January 2020

\section{Sinked}

- http://dx.doi.org/10.1136/annrheumdis-2020-217000

Ann Rheum Dis 2020;0:1-2. doi:10.1136/annrheumdis-2020-216983

ORCID iD

Brigitte Bader-Meunier http://orcid.org/0000-0001-8476-8196

\section{REFERENCES}

1 Saper VE, Chen G, Deutsch GH, et al. Emergent high fatality lung disease in systemic juvenile arthritis. Ann Rheum Dis 2019;78:1722-31.

2 Schulert GS, Yasin S, Carey B, et al. Systemic juvenile idiopathic arthritis-associated lung disease: characterization and risk factors. Arthritis Rheumatol 2019:71:1943-54.

3 Schroder K, Hertzog PJ, Ravasi T, et al. Interferon-Gamma: an overview of signals, mechanisms and functions. J Leukoc Biol 2004;75:163-89.

4 Silvennoinen 0 , Ihle JN, Schlessinger J, et al. Interferon-Induced nuclear signalling by JAK protein tyrosine kinases. Nature 1993;366:583-5.

5 Albeituni S, Verbist KC, Tedrick PE, et al. Mechanisms of action of ruxolitinib in murine models of hemophagocytic lymphohistiocytosis. Blood 2019;134:147-59. 